\title{
9. Internal witness support: the unmet challenge
}

\section{A. J. Brown and Jane Olsen}

\section{Introduction}

In recent decades, the protection of public interest whistleblowers from reprisals has become a major goal in Australian public administration. Practical theories for how this is to be achieved have, however, been slow to emerge. Much of the commitment to protecting whistleblowers has been confounded by the complexity of the issues that internal reporting provokes in the workplace, as well as by a range of conflicting stereotypes and assumptions about what whistleblowing involves, without the benefit of any detailed understanding of what really occurs.

At the same time, concepts of whistleblower protection have often been focused on the 'back end' of the problem. These include affording legal protection, such as relief from criminal or civil liability, and other responses such as the criminalisation of reprisals themselves. While important for their facilitating and deterrent effects, these responses serve only a likely minority of cases, in which whistleblowers have persevered to the point of attracting heavier risks or have cases fitting tight criteria for prosecution. Most importantly, these remedies are tailored to circumstances in which damage has already been done and in which the whistleblower has already become the victim of reprisals or other conflicts. Once experienced, these are likely to be problems from which an individual public officer's career and wellbeing might never fully recover, irrespective of legal protection and remedies. Little guidance has been available on how to minimise the number of public interest whistleblowers who find themselves in this position in the first place.

This chapter describes the extent to which Australian public sector agencies are making progress in pursuing this last, complementary approach to the risks faced by whistleblowers: the development of systems and procedures to help support and guide employees who report wrongdoing, as well as other employees, through the complex issues that inevitably accompany many whistleblowing cases. It therefore addresses the second of the two most crucial responses to whistleblowing in any agency-Chapters 5 and 8 having already addressed investigatory outcomes and capacity. How well are agencies addressing the risks of reprisal and other internal conflicts, managing the welfare of whistleblowers and remedying such problems that their best efforts have been unable to 
successfully prevent? To what extent is internal witness management becoming less of a secret 'art' and more of a 'science' (Brown 2001)?

The first part of this chapter examines the evidence provided by participating agencies about their internal witness support strategies - in response to the agency survey and, in the case study agencies, through the reported experiences of respondents to the internal witness, case-handler and manager surveys. The analysis outlines how many public sector agencies have procedures and organised systems for internal witness support and the scale of these systems, in terms of how many people they assist and how those people come to be supported.

The results show that organised systems for supporting and protecting internal witnesses are in relative infancy. Only 54 per cent of all agencies surveyed had relevant procedures and only 11 per cent of all agencies surveyed had a formal internal witness support system. Moreover, even within the group of case study agencies that did have a higher level of informal and formal systems, only a very small proportion of public interest whistleblowers were estimated as having ever come into contact with those systems. For these agencies, the number of employees who received organised internal witness support of this kind equated to perhaps 1.3 per cent of all public interest whistleblowers in those agencies and 6.5 per cent of all public interest whistleblowers who indicated via the research that they were treated badly by management or colleagues.

The reasons for this low take-up of organised or dedicated support services, even in the case study agencies, are likely to include:

- the low level of resources dedicated to such programs

- a previous shortage of data regarding the overall level of whistleblowing

- uncertainty or confusion about the types of employees intended to be targeted by programs

- an absence or inadequacy of procedural guidance on how employees should access the support, including an over-reliance on whistleblowers' self-identifying as such for the purposes of gaining support

- lack of management information systems for ensuring that all deserving whistleblowing cases can be identified and assessed for support

- inadequate or misapplied statutory definitions.

The second part of the chapter documents the sources of support experienced by public interest whistleblowers and the types of strategies or methods used. These analyses draw on data from the case study agencies. Not surprisingly, given the first results, the main sources of support that currently prevent more whistleblowers from suffering more than they do are not organised support programs, but informal social and professional networks, including family, friends, colleagues, union officials and supervisors. For those whistleblowers whose experience becomes more difficult, some sources of support, including 
professional counsellors and more formalised assistance programs, become more important, but supervisors, managers and investigation agencies become increasingly less so.

These analyses confirm the low uptake to date of more formalised support programs. They also reveal that case-handlers and managers - while not excessively optimistic about their own success - nevertheless continue to overestimate the extent to which organised or official sources of support are helping prevent worse outcomes. In other words, the extent to which whistleblower support is currently reliant on informal, social and professional networks does not appear to be properly appreciated. This creates a high risk that support will fail in any of the many circumstances in which the dual role of direct supervisors and line managers, described in Chapter 7, can turn from positive to negative. There are also signs that most support strategies can be somewhat reactive and attuned to bolstering the coping skills of whistleblowers in order to help them 'tough out' any difficult situations, rather than geared to management intervention against the sources of workplace conflict.

Third, the chapter examines the measures taken by agencies to assess the risks of reprisal and other major problems in whistleblowing cases and to respond to those risks should they be realised. These results provide like evidence that agency systems are currently largely reactive. In the majority of agencies, there is insufficient focus on thorough assessment of cases for the risks of what might go wrong, as opposed to providing support in the hope that nothing will. The reasons for this include a lack of prior data about the nature of the risks, such as would enable a more coherent approach to assessment. They also include, again, a lack of the internal management information systems needed to enable case-handlers to engage supervisors and other managers in an effective risk-management approach, by knowing more about more cases earlier, rather than waiting for problems to arise.

Finally, the analyses also show that when reprisal risks are realised, agency case-handlers and managers do not currently regard themselves as very well equipped or well placed to deal with them. Their evidence confirms the indications from Chapter 5 that, generally, allegations that whistleblowers have suffered reprisals or other management lapses are not currently handled well. The most common reasons for the fact such allegations are only rarely substantiated are not that reprisals have not occurred, but a range of difficulties in investigation, especially relevant to the fact that most reprisals are not acts for which individuals can be held culpable to a criminal standard of proof, but rather management reprisals and institutional reactions. Overall, the evidence indicates the need for a fresh approach to the handling of whistleblowing cases in which questions arise about the adequacy of the management response, including a new or different relationship between line and integrity agencies. 
A major aim of internal witness support strategies is to reduce the need for whistleblowers to take on an adversarial role when they disclose information about public interest wrongdoing - either in the course of the investigation or as instigators of their own support or as prosecutors of their own cause should they suffer detriment as a result of reporting. Instead, the aim is to enable public officials to play a more 'instrumental role' in the public sector's integrity systems (Whitton 1996) in which their duty is done, wrongdoing is addressed and rectified and they are able to emerge from their reporting role without undue stress and without having experienced, or caused, undue conflict. The term 'internal witness' itself, introduced in Chapter 1, is intended to connote this more instrumental role. The corollary of this role is that public sector agencies and the wider integrity system must accept a greater responsibility for ensuring the welfare of those who report and face up more rapidly to circumstances in which internal witness support requires more active intervention, or, should this fail, other remedies. These analyses suggest that while the prospects for greater success are good, the public sectors studied have a long way to go.

\section{Internal witness support programs}

\section{Agency procedures and systems}

The reasons for internal systems for supporting public interest whistleblowers and other internal witnesses are already well demonstrated. Chapter 5 reviewed the extent of the problems that can befall those who report wrongdoing, whether in the form of mistreatment, either from management or from colleagues, or other indirect impacts including those associated with natural tension and stress. In the case study agencies, whistleblowers' evidence of reprisals was confirmed largely by case-handlers and managers. Further, Chapter 6 demonstrated that as soon as a report of wrongdoing becomes more complex - for example, as soon as a case involves more serious wrongdoing, more alleged wrongdoers and more senior people - the risks of mistreatment rise exponentially.

The data presented in Part 1 nevertheless also demonstrate why these are not problems of which agencies can afford to wash their hands, and hence they demonstrate why internal support strategies represent a logical response. Contrary to many assumptions, the basic value of whistleblowing to organisational and public integrity is widely appreciated in public sector organisations, by fellow employees and managers alike. Notwithstanding the known incidence of reprisals and other conflicts, the principle is widely accepted that employees who report wrongdoing should not be made to suffer as a result. Contrary to many assumptions, the bulk of public interest whistleblowing begins and ends as an internal process, for which no-one other than the agency is currently responsible. In common law, employers already have a duty of care to employees to provide support and guidance through these processes. Finally, 
agencies know that it is in their own interests to facilitate internal reporting, as an alternative to external whistleblowing - and that this goal is made difficult if they have made no allowance for the protection of those who come forward. For all these reasons, how to support and protect whistleblowers is already a 'live' internal issue in most agencies.

How many agencies currently meet these needs with explicit policies, procedures and programs? The answer is: only a limited number. Of the 304 agencies who responded to the agency survey, 76 per cent (231 agencies) said that they had 'internal disclosure procedures' of some kind. These procedures are, however, often focused only on encouraging staff to make disclosures and dealing with how they should be investigated - as will be confirmed in more detail in Chapter 10. Tables 9.1 and 9.2 show that fewer agencies currently have procedures or systems that extend to the identification of employees needing 'active management support' as a result of their report or disclosure. Table 9.1 shows that only 54 per cent (162) of all agencies surveyed, including 61 per cent (70) of the agencies that participated in the employee survey, indicated that they had such procedures or systems. All 15 case study agencies indicated that they had such systems.

Moreover, when agencies indicated that they had relevant systems, these were often acknowledged to be only 'informal'. Only 34 per cent of all agencies surveyed had formal procedures for the provision of support, while Table 9.2 shows that only 20 per cent of agencies with procedures - 11 per cent of all agencies surveyed - supported these procedures with a formal program.

While the ability to provide a dedicated program is undoubtedly often constrained by issues of agency size, these figures indicate that the development of such programs is still only in its early stages in the Australian public sector. In the meantime, as also shown by Table 9.2, in the majority of agencies, the only available strategies for support lie with generalised employee welfare services (not tailored for whistleblowing) or support services that agencies believe are available from external or central government agencies. In fact, at the time of the survey, few if any external agencies provided any such support services in the jurisdictions studied, beyond general advice in relation to reporting and investigation processes. While there is a recognised need for support programs, there is also uncertainty - if not confusion - about what is available and how it should be provided. 
Table 9.1 Presence of agency systems for providing internal witness support (per cent)

\begin{tabular}{l|ccc}
\hline $\begin{array}{l}\text { Does your agency have procedures or systems } \\
\text { for identifying internal witnesses who may need } \\
\text { active management support as a result of their } \\
\text { report or disclosure? }\end{array}$ & $\begin{array}{c}\text { All agencies } \\
(\mathrm{n}=304)\end{array}$ & $\begin{array}{c}\text { Employee survey } \\
\text { agencies } \\
(\mathrm{n}=118)\end{array}$ & $\begin{array}{c}\text { Case study } \\
\text { agencies } \\
\text { (n = 15) }\end{array}$ \\
\hline No & $46(136)$ & $40(46)$ & - \\
Yes, formal procedures & $34(101)$ & $41(47)$ & $87(13)$ \\
Yes, informal procedures or systems & $20(61)$ & $20(23)$ & $13(2)$ \\
\hline Total & $100(298)$ & $100(116)$ & $100(15)$ \\
(Missing) & $(6)$ & $(2)$ & - \\
\hline
\end{tabular}

Source: Agency survey: Q25.

Table 9.2 Source of internal witness support in agencies (per cent) ${ }^{\mathrm{a}}$

\begin{tabular}{l|ccc}
\hline $\begin{array}{l}\text { Who does your agency rely on to support or } \\
\text { manage internal witnesses? }\end{array}$ & $\begin{array}{c}\text { All agencies } \\
(\mathrm{n}=162)\end{array}$ & $\begin{array}{c}\text { Employee survey } \\
\text { agencies } \\
(\mathrm{n}=70)\end{array}$ & $\begin{array}{c}\text { Case study } \\
\text { agencies } \\
\text { (n = 15) }\end{array}$ \\
\hline $\begin{array}{l}\text { General assistance or counselling services } \\
\text { available to all employees }\end{array}$ & $83(135)$ & $81(57)$ & $87(13)$ \\
$\begin{array}{l}\text { Our own informal internal witness support } \\
\text { systems }\end{array}$ & $46(74)$ & $57(40)$ & $47(7)$ \\
$\begin{array}{l}\text { External/central government agencies } \\
\text { Our own, formal internal witness support program }\end{array}$ & $24(39)$ & $17(12)$ & $13(2)$ \\
\hline
\end{tabular}

a Total does not add to 100 per cent because multiple responses were permitted.

Source: Agency survey: Q27.

Overall, these results show a cup that is more empty than full. The fact that many agencies do have systems and procedures for supporting internal witnesses confirms that the provision of support is recognised by many as important. The high proportion of agencies admitting to having no organised approach, however, indicates that many agencies are yet to scratch the surface in this direction. These results show that across the public sector, there could be considerable untapped potential for reducing the number of internal witnesses who feel mistreated, if only for the reason that many agencies are yet to make an organised effort.

The question becomes, what effort should be made? In some jurisdictions, as discussed in Chapter 11, all agencies are in theory under a legislative obligation to have such procedures and systems and their failure to do so already represents a technical statutory breach. The low take-up of procedures and systems indicates, however, a deeper problem than simply lack of organisational will and commitment. Even where statutory obligations exist, these are short on useful detail. Until this research, there have been little data on the nature of more formal programs and, most crucially, on whether they have any effect. The remainder of this chapter begins to broach these questions.

\section{Scale and uptake of internal witness support programs}

When agencies do have more formalised internal witness support programs, what is the size of these programs? Most importantly, how many internal 
witnesses do they reach? The answers confirm that even where they exist, more formal programs are currently relatively weak in terms of scale and-most importantly - accessibility.

Table 9.3 shows that whether formal or informal, most internal witness support programs currently function without any dedicated staff. Only 21 per cent (65) of all agencies could provide an estimate of having expended any staff resources on internal witness support, including contracted support, with the overall number of full-time equivalents (FTEs) very low. The case study agencies, all of which had procedures but only 10 of which provided staff support to a program, expended the highest number of staff resources, averaging 3.2 FTE per agency.

Table 9.3 Agencies with staff resources for internal witness support (FTE and mean)

\begin{tabular}{l|ccc}
\hline $\begin{array}{l}\text { Estimated number of staff (FTE) involved in } \\
\text { internal witness support and management }\end{array}$ & $\begin{array}{c}\text { All agencies } \\
\mathrm{n}=65 \\
\text { Total (mean) }\end{array}$ & $\begin{array}{c}\text { Employee survey } \\
\text { agencies } \\
\mathrm{n}=32 \\
\text { Total (mean) }\end{array}$ & $\begin{array}{c}\text { Case study } \\
\text { agencies } \\
\mathrm{n}=10 \\
\text { Total (mean) }\end{array}$ \\
\hline Central support unit/services & $65.0(1.0)$ & $40.0(1.2)$ & $12.0(1.2)$ \\
Other nominated support people & $67.1(1.0)$ & $16.1(0.5)$ & $6.0(0.6)$ \\
Contracted/external support people & $33.1(0.5)$ & $17.1(0.5)$ & $9.0(0.9)$ \\
Other & $17.0(0.3)$ & $9.0(0.3)$ & $5.0(0.5)$ \\
\hline Total & $182(2.8)$ & $82(2.5)$ & $32(3.2)$ \\
\hline
\end{tabular}

Source: Agency survey: Q30.

Table 9.4 Internal witnesses in receipt of active management support (number and means)

\begin{tabular}{|c|c|c|c|}
\hline $\begin{array}{l}\text { Number of internal witnesses who received active } \\
\text { management support under agency procedures } \\
\text { or systems }\end{array}$ & $\begin{array}{c}\text { All agencies } \\
(n=136)\end{array}$ & $\begin{array}{c}\text { Employee survey } \\
\text { agencies } \\
\text { (n }=54)\end{array}$ & $\begin{array}{c}\text { Case study } \\
\text { agencies } \\
(\mathrm{n}=14)\end{array}$ \\
\hline $2002-03$ & 408 (3.0) & $378(7.0)$ & $168(12.0)$ \\
\hline 2003-04 & 392 (2.9) & $356(6.6)$ & $144(10.3)$ \\
\hline 2004-05 & $427(3.1)$ & $388(7.2)$ & $192(13.7)$ \\
\hline Three-year period & $1227(9.0)$ & $1122(20.8)$ & 504136.0 \\
\hline
\end{tabular}

Source: Agency survey: Q36.

Table 9.4 sets out the number of individual employees who accessed agency support services in the three years before the survey, according to responses to the agency survey. These data are not limited to agencies with formal programs or dedicated staffing, but include all agencies. Slightly less than half of all agencies, and 84 per cent of all agencies with procedures for providing 'active management support', were able to estimate the number of employees assisted - totalling more than 1200 in the period. Across the 14 case study agencies that supplied data, all of which had procedures and most of which had programs, the estimated total of employees assisted was 504, averaging 36 employees per agency in the three years. 
These figures are not insignificant and confirm that, where programs exist, they do have a real workload. The scale of these programs is, however, placed in perspective by the employee survey data from earlier chapters. The 14 case study agencies had a combined total of approximately 330000 employees at the time of the research. Applying the averaged data for reporting rates arrived at in Chapter 2, which also held for the group of case study agencies, these agencies can be estimated as having had in the order of 38400 whistleblowers within their ranks in the two-year period (12 per cent of employees, 97 per cent of whom reported internally in the first instance). The total of 504 individuals estimated to have been provided with organised support by these agencies, in the three years, represents about 1.3 per cent of the estimated total whistleblower population.

Clearly, a large proportion of the whistleblowing described in Chapter 2 involves low-level reporting, with reduced risk of major conflict or management reprisal. Therefore, a more meaningful way of gauging the extent to which support programs are reaching their target audience is with reference to the number of whistleblowers who go on to report mistreatment. Across the case study agencies, on average, 20 per cent of whistleblowers went on to report having been treated badly by management or colleagues - giving an estimate in the order of 7700 individuals. On this measure, the total individuals estimated as being provided with organised support (in three years) still represents only 6.5 per cent of the population that can be estimated in retrospect as having been of potential need (in two years). The estimated size of the 'at-risk' population could be further refined in various ways, based on Chapter 6 . On any analysis, however, the gap between the number of employees provided with organised support and the likely number of whistleblowers in need is very large.

Why are such a small minority of at-risk whistleblowing cases - probably less than 6 per cent - making it onto the 'radar' of organised internal witness support programs? There is a range of possible explanations.

A first explanation is that the programs themselves, based on the levels of resources involved, have never been designed to operate at a large scale - even if agency resources would permit this. In part, this limited scale can be explained by the fact that, until now, little comprehensive evidence has existed to indicate how much whistleblowing goes on or what the size of the at-risk population might be. Further, it is logical for agencies to have designed any centrally organised and monitored program to meet perceived need - that is, to have planned to service only a limited proportion of those at risk, in order to focus on the worst types of known cases.

A second explanation is that there could be low staff awareness of the existence of the support program; while a third explanation is that even if they are aware of it, staff might be unwilling to access this support. 
All these explanations, however, beg the question of exactly what 'gateway' procedures are used to make support services available to employees who report. Tables 9.5 and 9.6 set out evidence for how internal witnesses currently access the available support and the types of individuals at which support programs are aimed.

Table 9.5 How internal witnesses access available support (per cent)

\begin{tabular}{l|ccc}
\hline & $\begin{array}{c}\text { All agencies } \\
(\mathrm{n}=162)\end{array}$ & $\begin{array}{c}\text { Employee survey } \\
\text { agencies } \\
(\mathrm{n}=70)\end{array}$ & $\begin{array}{c}\text { Case study } \\
\text { agencies } \\
\text { (n }=15)\end{array}$ \\
\hline $\begin{array}{l}\text { The internal witness must approach a designated } \\
\text { person in the agency }\end{array}$ & $27(43)$ & $30(21)$ & $27(4)$ \\
$\begin{array}{l}\text { The internal witness is approached by a } \\
\text { designated person in the agency }\end{array}$ & $23(38)$ & $27(19)$ & $27(4)$ \\
$\begin{array}{l}\text { Combination of the above } \\
\text { Our agency's procedures do not specify }\end{array}$ & $15(24)$ & $17(12)$ & $33(5)$ \\
Other & $19(31)$ & $20(14)$ & $7(1)$ \\
\hline
\end{tabular}

Source: Agency survey: Q28.

Table 9.6 Types of internal witnesses recognised as potentially needing support (per cent)

\begin{tabular}{l|c|c}
\hline $\begin{array}{l}\text { Which best describes the type(s) of internal } \\
\text { witnesses recognised by agency procedures or } \\
\text { systems as potentially needing active } \\
\text { management and support? }\end{array}$ & $\begin{array}{c}\text { Case-handlers and managers } \\
\text { combined } \\
\text { (n = 464) }\end{array}$ & $\begin{array}{c}\text { Integrity case-handlers } \\
\text { (n = 40) }\end{array}$ \\
\hline $\begin{array}{l}\text { Any internal witness/employee who provides } \\
\text { information about wrongdoing }\end{array}$ & $41(192)$ & $11(9)$ \\
$\begin{array}{l}\text { Any internal complainant/employee who reports } \\
\begin{array}{l}\text { Those whose case becomes or is likely to become } \\
\text { difficult to manage }\end{array}\end{array}$ & $30(138)$ & $10(4)$ \\
$\begin{array}{l}\text { Those identified as making a formal public } \\
\text { interest disclosure, protected disclosure or }\end{array}$ & $14(63)$ & $33(13)$ \\
whistleblowing report under legislation & $11(50)$ & $28(11)$ \\
$\begin{array}{l}\text { Those who ask to be, or consent to being, } \\
\text { identified as a 'whistleblower' }\end{array}$ & $5(21)$ & \\
\hline
\end{tabular}

Sources: Case-handler and manager surveys: Q46; integrity case-handler survey: Q43.

These data reveal some uncertainty about the best methods for identifying those employees who are in need of organised support and for admitting them to the program. As shown in Table 9.5, about 20 per cent of all agencies surveyed did not have any specified procedure for how employees should be identified. In these agencies, it is little wonder that the result is hit-and-miss. The same results also show a divergence between agencies that rely simply on whistleblower self-identification and agencies that rely on designated people approaching individual whistleblowers for inclusion. Less than 20 per cent of all agencies (but one-third of the case study agencies) use both methods.

In either case, however, a range of problems arises. If agencies are entirely reliant on employee self-identification, they face the problems of ensuring high staff awareness of the fact that support is available and persuading the more deserving staff to self-identify - not simply as a 'whistleblower', but as one unable to 
self-manage the situation. Given the evidence in Chapter 6 of the difficulties faced by whistleblowers in accurately assessing reactions and risks, self-identification alone is unlikely to be a reliable strategy, even if staff know of and are prepared to trust the program. Anecdotally, there is evidence that many deserving staff prefer not to access specialised support, at least initially, for fear of the possible negative effects of being tagged as a whistleblower. Conversely, any staff who see whistleblowing processes as possible alternative means for pursuing a personnel or private grievance could be very ready to enlist in such a program.

For all these reasons, best practice is more likely to be found among the 42 per cent of agencies (and 60 per cent of case study agencies) in which at-risk employees are identified and approached by designated people - whether as a sole method or in addition to self-identification. The data show, however, the significant challenges that still stand in the way of agencies extending organised support in this way. First, this relies on an overall understanding of the level of whistleblowing in the organisation, of the kind that is only now becoming available through research such as that outlined in this book. Second, Chapter 4 showed that the bulk of employee disclosures were made to supervisors and other managers in the first instance, being also where many of the most significant reprisal risks could lie. Just as this raises important issues for how investigations are triggered and carried out (Chapter 8), it also raises important issues about effective methods for early identification of those in need of support. In many agencies, the necessary management information systems might not exist that would enable monitoring of incoming cases for assessment as to likely need for intervention - or such systems might not exist in relation to complaints and internal workplace issues. The creation of effective systems for the receipt and notification of all such disclosures, to ensure that appropriate responses can include intervention for the purposes of internal witness support, is an important priority.

Table 9.6 also shows a diversity of opinions, within agencies, as to what types of employees are eligible for support. These data come from case-handlers and managers in the case study agencies, as well as from case-handlers from those integrity agencies from which more than one response was received. There was significant variation in who case-handlers and managers thought were the intended focus of protection, indicating some differences between agencies, but also conflicting assumptions within agencies since, in any one agency, at most only two-thirds of respondents selected the same response. While overall the largest single group of respondents chose the least restrictive definition, and the group sizes reduced in line with increasing restrictiveness, the fact remains that they could not all be right. 
Similarly, in integrity agencies in which more than one case-handler responded, at most, only three-quarters of the respondents selected the same answer. Most concerning was the fact that, unlike the case study agency case-handlers, 61 per cent of integrity agency case-handlers selected one of the two most restrictive definitions. This could suggest that integrity agency case-handlers tend only to see cases that fit these definitions. Their assessment could, however, also reflect the reality - as indicated by the data already outlined - that only a very narrow band of employees who report wrongdoing are in fact coming into contact with agency support systems.

Finally, these analyses point to problems in the relationship between legislative requirements and agency practice, in the extent to which statutory definitions of 'public interest disclosures' are helping or hindering the provision of internal support. As outlined in Chapters 1 and 2, the amount of public interest whistleblowing that occurs, which should logically trigger the basic statutory provisions for whistleblower protection that exist in most jurisdictions, is much higher than is currently being reported under that legislation (where reporting obligations exist). This could be explained by the restrictive nature of some statutory definitions; by misunderstanding or misapplication of the definitions within agencies; or, again, by simple lack of management information about the true number of internal disclosures that satisfy those definitions. The key problem is that very little purpose exists for such definitions, if not to ensure that as many at-risk whistleblowers as possible (potentially, almost any) can be identified, assessed and, where necessary, provided with an appropriate level of internal witness support. The fact that current statutory frameworks are providing only limited assistance - and some barriers - to the meeting of this goal becomes an important issue for discussions of legislative reform, taken up in Chapter 11.

\section{Sources and methods of internal witness support}

\section{Who does provide support?}

Given that relatively few agencies have formal support programs, and that few internal witnesses come into contact with them, how is that more whistleblowers do not report mistreatment or reprisals? While the previous section analysed mainly evidence about organised and formalised systems for providing support, it was always presumed that the functions of supporting and managing whistleblowers were likely to involve a wide variety of organisational actors and that these could - and often should-include the direct supervisors and managers of internal witnesses themselves (Brown et al. 2004). In the case study agencies, whistleblowers, case-handlers and managers alike were surveyed about who played important roles in providing assistance and support and offered a 
range of options in addition to organised support programs. Integrity agency case-handlers were asked the same questions.

The internal witness survey asked who provided the greatest help and support-after the respondent provided their original information about wrongdoing and then after they experienced any 'bad treatment or harm'. Table 9.7 shows the results, ranked in order of the people or unit recorded by the greatest number of whistleblowers as providing support after their initial report $(\mathrm{AR}=$ 'after report'), with the second percentage indicating the proportion of those who nominated the same people or unit as having provided support, after they had experienced any bad treatment or harm ( $\mathrm{AH}=$ 'after harm'). Bold figures highlight a decrease in the proportion of respondents who nominated that source as providing support after experiencing harm. Both sets of results are broken down according to how respondents said they were treated overall by management and co-workers, to indicate how the pattern of support fell, depending on the source of the perceived bad treatment.

The small group who reported being treated badly only by co-workers drew on the least number of sources. Those who were treated well or the same by management and co-workers drew on more sources of support. The largest number of sources was accessed by those treated badly by management. The overall pattern is one of greatest reliance on the existing personal, social and professional networks that surround the employee, at least in the first instance. This was especially true of those claiming bad treatment by management, who relied especially heavily on their own work colleagues for support, as well as on union support. Those who said that they were not treated badly nevertheless found the greatest support among other work colleagues, and also their supervisor, when the going got tough.

One respondent wrote: '[T]he best support is psychological and comes from colleagues with previous similar experiences.' Another respondent, however, highlighted the difficulty of maintaining collegial support in the longer-term:

Many work colleagues supported me initially. This included phone calls and providing information to me about what was happening in the workplace (because I was suspended). I made a list of these supporters so that I could thank them when it was all over. However, about a year onwards when the matter finally concluded-I had crossed off most of the supporters on my list. Fearful of losing their jobs (some reported being threatened with this) they simply felt the risk of being aligned with me was too great. 
Table 9.7 Sources of help, assistance and support to whistleblowers (per cent) ${ }^{\mathrm{a}}$

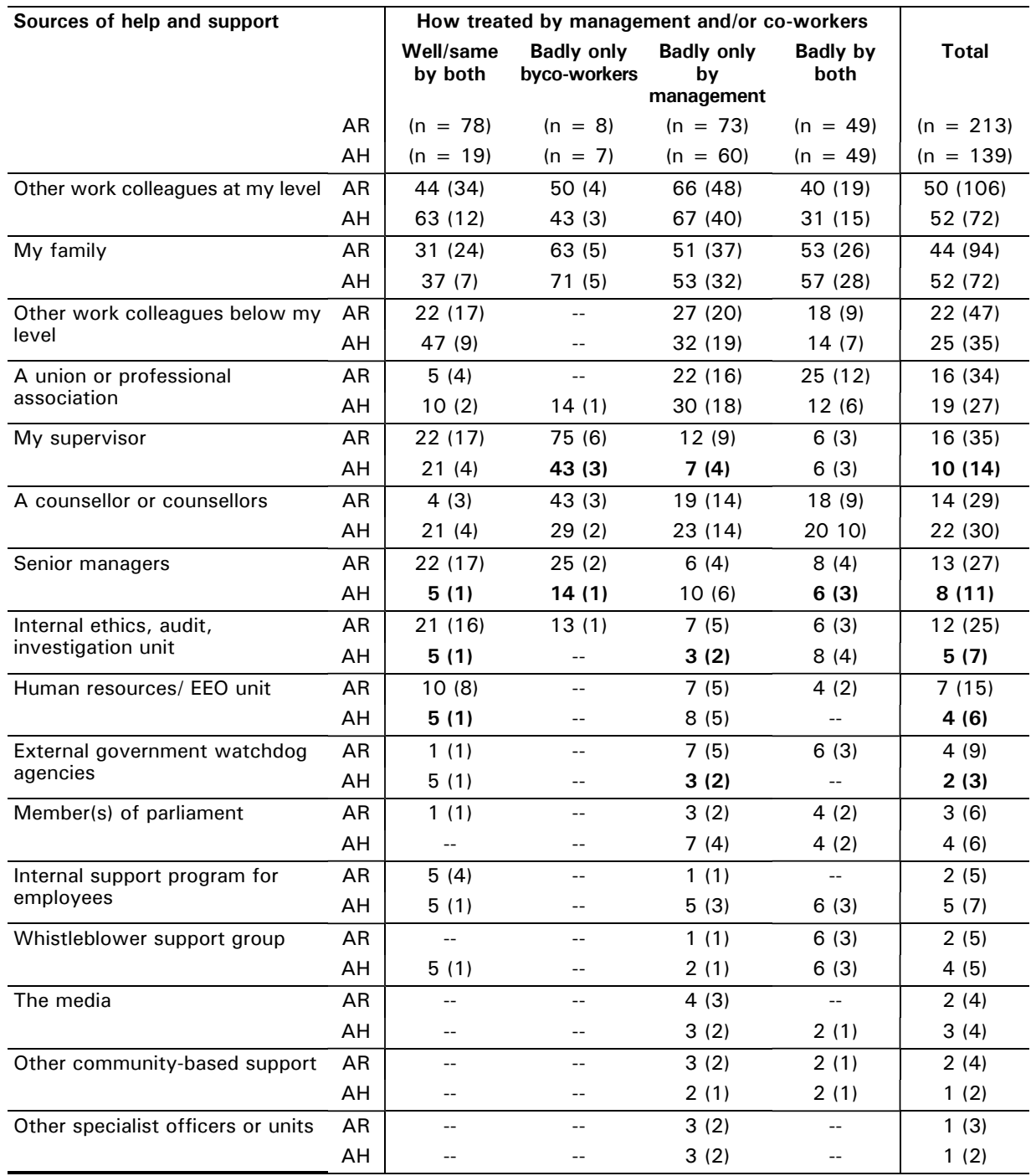

a Total does not add to 100 per cent because multiple responses were permitted.

Note: Bold highlights decreases in the percentage of respondents indicating support from this source after bad treatment or harm (AR).

Source: Internal witness survey: Q47 ('Which of the following assisted or supported you after you reported?' [AR]); Q57 ('Which gave you good help and support after you experienced bad treatment or harm?' [AH]).

Table 9.7 also shows that whistleblowers who were treated badly by colleagues fell back heavily on their own family for support. Importantly, they also drew heavily on their supervisor and management and were likely to be the first to access professional counselling support. Counsellors became increasingly important for all groups once problems emerged. For those treated badly only 
by colleagues, however, the fact that they did not go on to seek other forms of support suggests that they were able to 'ride out' the storm using these basic resources.

Apart from the diffuse and informal nature of support, four results are particularly noteworthy. First, as expected, internal witness support programs featured only weakly as a source of support, nominated by only 2 per cent of all respondents and by only 5 per cent of those respondents who experienced bad treatment or harm. While the different modes of data collection meant no similarity was likely, it was a notable coincidence that those proportions aligned closely with the results from the agency and employee survey comparisons in the previous section. The clearest explanation for this result is that few respondents had ever come into contact with these programs, even though most of these agencies said they had them and agreed to encourage all known beneficiaries of these programs to participate in the survey. It is also possible that respondents did not necessarily see the 'program' as having provided support, even though it was in fact responsible for the support they received from others, such as counsellors, managers or peer support officers.

Any direct evidence as to the real performance of these programs is mixed. As indicated in Chapter 5, while these programs did become more important as a source of support for those who experienced bad treatment, 4 per cent of public interest whistleblowers also indicated that the internal program was responsible for that bad treatment. This is a sure sign that even when it was accessed, the program fails to meet expectations; and both results could indicate that the program is accessed only too late, after problems have become intractable. Further analysis of the performance of these programs will await the second report from this project, and further research.

The second notable result is that internal investigators did not feature strongly as support mechanisms, other than in the first instance by those who did not go on to report being treated badly. This suggests that internal investigators could have been very valuable as sources of support in the first instance and helped whistleblowers prevent a range of problems. The results also show, however, that as problems arose - often no doubt linked to an adverse investigation outcome - the ability and/or willingness of investigators to provide support fell away. This tends to confirm the problem discussed earlier, and in the preceding chapter, that while investigators are crucial, their institutional role is not compatible with continuing support.

The third result was that this pattern was broadly repeated in relation to external watchdog agencies, which had a minimal support role throughout and one that reduced rather than became stronger. This result confirms that, even though a large number of agencies cite external agencies as an important source of support, in fact, this does not occur. As with internal support programs, it could be that 
this happens partly for the reasons suggested in Chapters 4 and 5: few whistleblowers persist with a disclosure to an external agency unless they are already experiencing bad treatment or reprisals, by which time it is already too late for the external agency to positively assist. Reprisal responses are also discussed further in the next section.

Finally, the results highlight the crucial role of managers, including direct supervisors. Chapter 7 highlighted their dual roles as the biggest potential source of official support for whistleblowers and also, potentially, as the biggest source of their problems. This duality is demonstrated clearly by the data. One respondent to the internal witness survey wrote that 'managers were very understanding and supportive of the need to properly and thoroughly investigate [the] wrongdoing' - again highlighting the connection between investigation process, outcome and perceived support. Even without feeling he or she had been positively mistreated, however, another respondent 'generally felt a lack of support by supervisor (senior manager), and [the] organisation [in] general', writing that 'two new senior managers viewed my action in a negative light and questioned my course of action, suggesting it would put the organisation in a negative light'.

While this duality of roles means that first and second-level managers could be the most significant source of reprisal risk or exposure in any given situation, there is clearly no wisdom in excluding them from the overall process of internal witness management - even if this were possible. This is because they could also be the most crucial source of support and protection. The evidence from case-handlers and from managers themselves reinforces this complex problem.

\section{Who do case-handlers and managers see as providing support?}

Table 9.8 sets out the responses of case-handlers and managers, from the same case study agencies, showing the relative importance of a similar range of people and units in managing the welfare of employees who report wrongdoing. Again, these are ranked in order of most to least important, according to the combined sample of case-handlers and managers, with most options rating as at least somewhat important. Bold results indicate variations from the rank order. The low variation between the rankings given by case study agency case-handlers and managers provides significant validation of the results, since these groups can bring quite different perspectives. Integrity agency case-handlers had quite different views to others.

While there are many similarities with the relative importance of different sources as indicated by whistleblowers, there are also some striking differences. None of the aggregated assessments of the internal case-handler, manager or integrity case-handler groups proved fully accurate in respect of the relative importance 
of the major sources, when compared with the internal witnesses. A large proportion of the internal witness sample had experienced mistreatment and, by definition, could have had less experience of good support sources that helped prevent any perceived mistreatment at all. Even taking this into account, however, the first striking difference is that all of these groups tended to overestimate the importance of official sources of support, especially supervisors and managers, relative to the more informal sources. The partial exception was the integrity case-handler group, which rated 'supervisors' as somewhat less important and instead rated 'senior managers' and 'the $\mathrm{CEO}^{\prime}$ ' as very important.

This result is not surprising from respondents whose institutional roles require some faith in the working of their own management systems - for example, integrity case-handlers also rated their own agencies as much more important than any other group, including the internal witnesses. Nevertheless, just as Chapters 5 and 6 revealed significant mismatches in understanding between internal witnesses and these groups, these results suggest that those responsible for managing whistleblowing currently see support arrangements more as they hope them to be than as they probably are. In this complex field, any overconfidence about the relative effectiveness of the official support systems clearly carries a number of dangers.

Particularly important is that internal witness support programs were rated as playing the fourth most important role overall and both groups of case-handlers rated them third. These results highlight that while those responsible for whistleblowing might place great stock in these schemes, and might even be rightly optimistic about their potential, their weak relevance in the actual experience of whistleblowers is not something that has yet been grasped at official levels (at least until now). Based on the evidence set out so far, the assumption that these programs can provide the cornerstone of support-especially in those circumstances in which a whistleblower's supervisors or other managers are compromised-is a potentially dangerous one, at least given the current state of these programs and associated agency systems.

In contrast, emphasising the preference for official support over informal sources, all groups underestimated unions as a source of support compared with their real importance in the experience of many whistleblowers. 
Table 9.8 People with an important role in managing employee welfare (mean)

\begin{tabular}{|c|c|c|c|c|}
\hline $\begin{array}{l}\text { Which of the following people have an important role } \\
\text { in managing the welfare of an employee/public } \\
\text { employee who has reported wrongdoing? } \\
1=\text { not important } \\
2=\text { somewhat important } \\
3=\text { very important }\end{array}$ & $\begin{array}{c}\text { Case-handlers } \\
(\mathrm{n}=254)\end{array}$ & $\begin{array}{l}\text { Managers } \\
(\mathrm{n}=374)\end{array}$ & $\begin{array}{c}\text { Case-handlers } \\
\text { and } \\
\text { managers } \\
\text { combined } \\
(\mathrm{n}=628)\end{array}$ & \begin{tabular}{|c|} 
Integrity \\
case-handlers \\
(n = 64)
\end{tabular} \\
\hline The employee's supervisor & 2.81 & 2.87 & 2.85 & 2.67 \\
\hline The employee's family and/or friends & 2.78 & 2.79 & 2.78 & 2.80 \\
\hline Senior managers & 2.64 & 2.68 & 2.66 & 2.88 \\
\hline $\begin{array}{l}\text { Internal support program for employees who report } \\
\text { wrongdoing }\end{array}$ & 2.65 & 2.56 & 2.60 & 2.78 \\
\hline Internal staff counselling or welfare service & 2.48 & 2.42 & 2.44 & 2.48 \\
\hline Peer-support person for employees who report & 2.45 & 2.41 & 2.43 & 2.63 \\
\hline Human resources/equity and merit unit & 2.31 & 2.37 & 2.35 & 2.45 \\
\hline External staff counselling or welfare service & 2.34 & 2.29 & 2.31 & 2.45 \\
\hline The CEO (or equivalent) & 2.16 & 2.27 & 2.22 & 2.72 \\
\hline Internal audit, fraud, investigation or ethics unit & 2.15 & 2.11 & 2.13 & 2.33 \\
\hline Unions or professional associations & 2.15 & 2.07 & 2.10 & 2.17 \\
\hline Whistleblower support group(s) & 2.02 & 1.95 & 1.98 & 2.08 \\
\hline External government watchdog agencies & 1.67 & 1.53 & 1.59 & 2.20 \\
\hline Other community-based support services & 1.61 & 1.54 & 1.57 & 1.80 \\
\hline Lawyers & 1.45 & 1.40 & 1.42 & 1.53 \\
\hline Member(s) of parliament & 1.21 & 1.21 & 1.21 & 1.39 \\
\hline Journalists & 1.16 & 1.10 & 1.12 & 1.31 \\
\hline
\end{tabular}

Note: Bold results highlight mean ratings that differ from the combined case-handler and manager rank order.

Sources: Case-handler and manager surveys: Q43; integrity case-handler survey: Q50.

While the aggregate views of case-handlers and managers demonstrate this general overconfidence in official support, some particular results show an important counter-trend. The fact that integrity case-handlers rated supervisors as comparatively less important suggests a recognition of the duality of their role and the need for stronger oversight of managerial responses to whistleblowing in the experience of integrity agencies. Contrary to much of the evidence from the agency survey in Chapter 8, none of these groups (including case-handlers themselves) rated internal investigation staff as very important. This could represent something of an underestimate of their importance, but it accords with whistleblowers' overall experiences and an operational recognition of the risk of conflict between investigation and support roles.

Overall, these data again provide no evidence that increased investment in organised strategies of internal witness support is ineffective. Rather, they suggest there is a danger in any assumptions that the current level of investment, or the adequacy of associated information and management systems, is sufficient. In those circumstances in which supervisors and other senior managers recognise that wrongdoing has been reported and do not feel compromised by the information disclosed, in accordance with the risk factors revealed in Chapter 6 , there is a good chance that the combination of formal and informal sources 
of support can carry many whistleblowers through. The primary challenge is that as soon as there is a risk of conflict with supervisors and other managers, and the normal management chain becomes less reliable as a source of support, alternative internal witness support programs and systems are clearly not yet filling the breach.

\section{What are the strategies for support?}

This chapter has so far discussed 'support' as a general concept. Indeed, the research has generally confirmed that support to whistleblowers facing a range of complex processes and conflicts is more important as a primary organisational response than a focus on 'protection' from direct reprisals. As shown in Chapter 5, direct personal reprisals are relatively rare, compared with the more indirect forms of stress, conflict and managerial mistreatment that represent more common outcomes for many whistleblowers and from which the risks of more direct reprisals then arise.

'Support, support, support' was a simple, yet common sentiment expressed by respondents to the internal witness survey when asked how they could be better provided with assistance. One internal witness survey respondent was able to summarise, with some detachment, some of the key forms of support involved:

I think the main components in supporting these people are: keeping them informed; praising them for their co-operation; ensuring confidentiality; providing them with counselling if the wrongdoing is extremely serious; always provide a listening ear for when they need to express concerns or just discuss the matter.

These comments also reflect a little-recognised fact: when an employee has been working in close proximity with serious wrongdoing - potentially for some time and potentially in a manner in which they themselves feel compromised or responsible for its continuation - such circumstances can be sufficient to constitute a traumatic level of stress. In other words, in serious cases, many whistleblowers might not need to experience any active or passive mistreatment from managers or colleagues before entering a state in which they need intensive personal and professional support.

What methods do those involved with whistleblowing regard as the most effective for managing the welfare of those who report?

Table 9.9 sets out the opinions of those case study agency case-handlers and managers and integrity agency case-handlers who indicated direct knowledge of the available strategies for providing active support. All of the support methods offered were rated as at least fairly effective, with only 'workers' compensation' tending towards a rating of 'fairly ineffective'. Of the 521 case 
study agency respondents who completed this question, only one indicated any knowledge of any other method used, beyond the items offered by the survey.

Table 9.9 Methods for managing employee welfare (mean)

\begin{tabular}{l|c|c|c|c}
\hline $\begin{array}{l}\text { How effective are the following methods for } \\
\text { managing and ensuring the welfare of staff/public } \\
\text { employees who report wrongdoing? }\end{array}$ & $\begin{array}{c}\text { Case-handlers } \\
(\mathrm{n}=209)\end{array}$ & $\begin{array}{c}\text { Managers } \\
(\mathrm{n}=312)\end{array}$ & $\begin{array}{c}\text { Case-handlers } \\
\text { and managers } \\
\text { combined } \\
\text { (n = very effective; }\end{array}$ & $\begin{array}{c}\text { Integrity } \\
\text { case-handlers } \\
\text { (n }=45)\end{array}$ \\
2 fairly effective; & & & & \\
$3=$ fairly ineffective; & & 1.42 & 1.46 & 1.68 \\
$4=$ very ineffective & 1.53 & 1.62 & 1.58 & 1.71 \\
\hline $\begin{array}{l}\text { Maintaining confidentiality of the employee's } \\
\text { identity }\end{array}$ & 1.51 & 1.76 & 1.76 & 1.85 \\
Advice and counselling & 1.75 & 1.89 & 1.93 & 1.93 \\
Provision of information about the investigation & 1.98 & 1.94 & 1.93 & 1.90 \\
Special access to senior management & 1.93 & 2.01 & 2.01 & 1.81 \\
Support for the family of the staff member & 2.03 & 2.03 & 2.04 & 2.15 \\
Advice and counselling to co-workers and other & 2.04 & 2.15 & 2.15 & 1.80 \\
staff & 2.15 & 2.50 & 2.51 & 2.53 \\
Special leave/transfer arrangements & 2.51 & & \\
Physical protection & & & \\
Workers' compensation & & & \\
\hline
\end{tabular}

Sources: Case-handler and manager surveys: Q47; integrity case-handler survey: Q44.

While the recognition given to these methods is largely self-explanatory, further issues are raised if any of these methods - however effective-is simply not available. This is clearly the case in respect of the strategy identified above as most effective: confidentiality. Indeed, as is seen in the review of agency procedures provided in the next chapter, and in many statutory provisions, many organisations place a premium on trying to maintain confidentiality to the maximum possible extent. Elsewhere, 85 per cent of all respondents to the case-handler and manager surveys (Q56) rated the protection of an internal witness's identity as either very or extremely important.

Certainly, for as long as it can be preserved, confidentiality provides whistleblowers, case-handlers and managers with crucial time to assess risks and plan options. Even once a whistleblower's identity becomes known or suspected, confidentiality requirements can assist as a strategy for suppressing workplace conflict, by helping contain workplace gossip and reminding staff that the individual personalities involved are less important than the real issues (Brown et al. 2004). A question arises, however, as to what support remains available when confidentiality ceases to be possible. That this is usually the case, sooner or later, is reflected in the results in Chapter 6, in which the number of people who knew that the whistleblower had reported was not a risk factor for identifying whether, ultimately, they were likely to suffer mistreatment.

It is notable in Table 9.9 that once confidentiality ceases to be an option, the next four methods are all aimed at assisting whistleblowers to better self-manage their role in the process, rather than addressing objective risks such as potential 
action from and reactions of affected managers or staff. That 'advice and counselling to co-workers and other staff' was rated as the fifth most effective method and as only 'fairly effective' overall is an indicator that many strategies remain relatively passive in their approach to managing the risks that follow whistleblowing. If a major perceived source of stress or conflict is the reaction from co-workers, this result suggests relatively low success to date in efforts to confront such risks head-on. If a major perceived source of problems is the reaction of a supervisor or other managers - as Chapters 5 and 6 indicate - the result is even more worrying, again suggesting a strategy of helping the whistleblower to 'tough it out' rather than workplace intervention. The data suggest a continuing need for the development of more effective intervention strategies once confidentiality ceases to be practical (see, for example, NSW Ombudsman 2005).

The relatively low rating given to 'workers' compensation' suggests that rather than being ineffective, measures to compensate internal witnesses for problems endured might simply be less available. As discussed in Chapter 11, while most public interest disclosure legislation is predicated on ensuring that employees who suffer detriment as a result of whistleblowing are able to seek compensation, the legal procedures are typically onerous. There are no known cases in which such applications have been attempted under this legislation, let alone successful. How effective, overall, are agencies' strategies for managing the welfare of internal witnesses in the view of case-handlers and managers? Table 9.10 shows that case-handlers and managers have a relatively sober view of their agencies' success. On average, case-handlers rate their own organisations as only 'somewhat' effective. Managers had only a slightly more positive view. In contrast, case-handlers in integrity agencies had a very negative view of how well organisations in their jurisdiction were managing whistleblowers' welfare, with 89 per cent also indicating that they believed that the proportion of organisations that were effective was about half or less (integrity case-handler survey: Q58). Like the agency case-handlers, the respondents from the integrity agencies also viewed the performance of their own agency's systems as only 'somewhat' effective (Q60; mean = 3.07, $\mathrm{n}=75)$.

Table 9.10 Perceived effectiveness in managing whistleblower welfare (mean)

\begin{tabular}{l|c|c|c|c}
\hline $\begin{array}{l}\text { Overall, how effective do you believe your } \\
\text { organisation is/public sector organisations in your } \\
\text { jurisdiction are at managing the welfare of } \\
\text { employees who report wrongdoing? }\end{array}$ & $\begin{array}{c}\text { Case-handlers } \\
(\mathrm{n}=295)\end{array}$ & $\begin{array}{c}\text { Managers } \\
(\mathrm{n}=430)\end{array}$ & $\begin{array}{c}\text { Case-handlers } \\
\text { and managers } \\
\text { combined } \\
(\mathrm{n}=725)\end{array}$ & $\begin{array}{c}\text { Integrity } \\
\text { case-handlers } \\
(\mathrm{n}=76)\end{array}$ \\
\hline $\begin{array}{l}1=\text { not at all; } \\
2=\text { not very; }\end{array}$ & 3.00 & 3.18 & 3.10 & 2.41 \\
$\begin{array}{l}3=\text { somewhat; } \\
4=\text { very; } \\
5=\text { extremely }\end{array}$ & & & & \\
\hline
\end{tabular}

Sources: Case-handler and manager surveys: Q60; integrity case-handler survey: Q57. 
A better understanding of the precise methods and strategies used to provide effective support is a priority for further research. The project's second report will probe these more deeply. While there is evidence that strategies for managing the workplace effects of wrongdoing and whistleblowing are in rapid development, it is clear that they remain less 'a science' than 'an art' (Brown 2001; Brown et al. 2004). Many outcomes depend on the varying ethical and professional standards of individual managers, the personal coping capacities of whistleblowers, the strength of their personal relationships and a range of other random influences, including luck. For these reasons, the strategies used and their relative effectiveness are also important subjects for more rigorous evaluation by agencies themselves. When asked about exit and follow-up procedures involving internal witnesses, only one-fifth of all case-handlers and manager respondents from the case study agencies ( 21 per cent) indicated an awareness of such procedures and only 3 per cent indicated that they included any 'follow-up evaluation'. There is much that agencies can do to improve their own knowledge about what works and what doesn't within their own organisation.

\section{Reprisals, risk assessment and responses}

The final analyses in this chapter concern how agencies respond to reprisals and reprisal risks. As shown in Chapters 5 and 6, and noted again above, the anticipation and management of reprisal risks are central tasks in the process of internal witness support. Contrary to the expectations of many case-handlers and managers, the major source of risks of mistreatment against whistleblowers (real and perceived) is management itself, with direct reprisals and mistreatment by colleagues arising in only a relatively small proportion of cases.

By their nature, most of the types of reprisal described in Chapter 5 also do not relate to 'cleanly' identifiable risks and events, for which particular individuals can be easily held directly responsible. Instead, risks of mistreatment are often interwoven with failures in management support - for example, when no attempt is made to manage workplace tensions and conflicts, or these attempts fail or are withdrawn at a critical stage. While direct 'payback' actions are a risk, mistreatment can take other forms - for example, actions to discipline or marginalise an employee due to failures in their work performance, when these failures could be real but have also been exacerbated by the organisation's own failures in managing the whistleblowing incident.

The present research therefore collected evidence not only about agencies' positive approaches to assisting internal witnesses, but their readiness to deal with negative possibilities - in other words, their strategies for anticipating, managing and dealing with things that could go wrong. The results indicate these to be areas of particular procedural weakness in many agencies. 


\section{Reprisal risk assessment}

Earlier, it was seen that only about half of all agencies surveyed in the project had procedures for supporting internal witnesses. Only about one-third of all agencies surveyed had formal procedures. The agency and case-handler and manager surveys also asked if agencies had any routine procedures for assessing the risks of reprisals being taken against internal witnesses.

The agency survey revealed this to be an area of particular weakness. Seventy per cent of the 304 agencies said plainly that they did not carry out any assessments of reprisal risk. Moreover, the bulk of the remainder claimed to have only 'informal/unwritten' procedures for risk assessment, with only 46 agencies (15 per cent of all agencies) able to nominate who had responsibility to 'undertake or coordinate' these risk assessments and only six agencies (2 per cent) indicated that any of their risk-assessment procedures were formal.

Across those agencies able to indicate who was responsible for assessing reprisal risk, this role was shared between a range of officers: designated disclosure officers, internal audit and investigations staff, CEOs and senior managers and staff involved in internal witness support. In the same way that support roles are shared between these different actors, this tends to suggest, to differing extents, that the assessment of reprisal risk occurs on an 'as needed' basis in the normal, ad hoc handling of cases.

The agency survey, however, also showed it is not safe to assume that the assessment of reprisal risks simply forms an automatic part of the management of whistleblowing cases and therefore does not need specific procedures. As set out in Table 9.11, agencies were also asked whether, irrespective of whether they had other procedures or staff for providing internal witness support, they had any staff responsible for ensuring that internal witnesses were protected from reprisals.

Table 9.11 Agencies with staff for protecting employees from reprisals (per cent)

\begin{tabular}{|c|c|c|c|}
\hline $\begin{array}{l}\text { Does your agency have staff responsible for } \\
\text { ensuring that internal witnesses are protected } \\
\text { from reprisals? }\end{array}$ & $\begin{array}{l}\text { All agencies } \\
(n=294)\end{array}$ & $\begin{array}{l}\text { Employee survey } \\
\text { agencies } \\
(\mathrm{n}=115)\end{array}$ & $\begin{array}{l}\text { Case study } \\
\text { agencies } \\
(n=15)\end{array}$ \\
\hline No & $30(89)$ & $23(26)$ & 0 \\
\hline Yes & 70 (205) & 77 (89) & $100(15)$ \\
\hline Investigation staff ${ }^{\text {a }}$ & 45 (93) & $55(49)$ & $60(9)$ \\
\hline $\begin{array}{l}\text { The internal witness's supervisor and/or line } \\
\text { managers }{ }^{\text {a }}\end{array}$ & 48 (99) & $34(39)$ & $60(9)$ \\
\hline Support staff ${ }^{\text {a }}$ & $30(62)$ & 49 (44) & $33(5)$ \\
\hline Other $^{\text {a }}$ & $36(73)$ & $34(30)$ & $40(6)$ \\
\hline
\end{tabular}

a Total below line does not add to 100 per cent as multiple responses were permitted.

Source: Agency survey: Q38. 
Thirty per cent of all agencies responded that they had no such staff. This was a startling admission of weakness, given the options included their own investigation staff, discussed above, and the whistleblower's own supervisor and line managers, who are present in all agencies and have many legal responsibilities to protect their employees. If no-one is considered responsible for protecting whistleblowers from reprisals in these agencies, it is safe to assume that no-one is considered responsible for assessing the risk of reprisals or doing anything to prevent or minimise them.

A more detailed picture can be seen from the 15 case study agencies, all of which said they had staff responsible for protecting internal witnesses from reprisals. Ten of these agencies responded in the agency survey that they had risk-assessment procedures, eight of which could also nominate who was responsible, but only agency whose procedures were formalised.

Even this picture might be optimistic, however, as an indicator of agency practice. Across the case study agencies, 80 per cent of all respondents to this item in the case-handler and manager surveys said either that no-one carried out any reprisal risk assessments in their organisation (32 per cent) or they did not know whether anyone did (48 per cent). This result was not significantly different for case-handlers who were more likely to know and came notwithstanding that the bulk of these respondents were from agencies that claimed to have risk-assessment procedures.

The case-handler and manager surveys also revealed uncertainty about when any conscious assessment of reprisal risks did, or should, occur. Of the 147 respondents who indicated knowledge of risk assessments, 8 per cent did not know at what point they usually occurred. A substantial proportion (49 per cent) indicated that it was most usual for risk to be assessed either when the employee first expressed fears (37 per cent) or only after they reported real detriment from a reprisal (12 per cent); 40 per cent indicated that it was when the employee first provided the original information about wrongdoing. A similar pattern was found among integrity agency case-handlers.

These results confirm that even if it does occur, conscious assessment of the risks of reprisal can often follow only when whistleblowers start to experience stress or problems, or might be triggered by those cases in which whistleblowers themselves anticipate risks. Together, the results highlight the extent to which the support strategies described in the earlier parts of the chapter could be predicated on luck - that is, hoping for the best that problems will not arise - rather than proactive assessment of the risks before they emerge. Chapter 6 highlighted that it could also be those whistleblowers who appeared to see no risks, and who were therefore by definition more 'naive' or trusting, who were least well served by this reactive approach and were in most need of support systems that included more routine, objective assessment from the outset. Chapter 
6 also highlighted some of the key risk factors that can now be more readily used to frame a more proactive approach, based on the present research.

\section{Responses to reprisals}

Finally, the most crucial form of support that a whistleblower can come to expect from their organisation is effective action if problems unravel to the stage of a direct reprisal or other inappropriate workplace reaction - including management reactions - to the circumstances provoked by a report. As with reprisal risk assessment, there is evidence that many agencies have made little or no provision for this worst-case scenario. Just as an alarming number of agencies responded to the agency survey that they had no staff responsible for protecting internal witnesses from reprisals, more than half of all agencies surveyed ( $n=158$, or 54 per cent) had no procedures for responding to reprisals and only 20 per cent of all agencies $(n=60)$ reported having any specific practices and procedures for the investigation of reprisals if they occurred.

The evidence from the case-handler and manager surveys suggests that even in the case study agencies, where most respondents felt the agency was at least fairly effective in supporting whistleblowers, there is much lower confidence in agencies' ability to provide support when the 'going gets tough'.

As shown in Chapter 5, many respondents to these surveys had direct experience of reprisal allegations: 50 per cent of the case study agency case-handlers ( $\mathrm{n}=$ 149), 38 per cent of the managers $(n=165)$ and 72 per cent of the integrity agency case-handlers $(n=53)$. The majority of these respondents indicated that in at least some cases, they believed the alleged reprisal had in fact occurred, with a considerable degree of congruence between the types of reprisals, or bad treatment, that were considered most common by case-handlers, managers and whistleblowers alike.

When asked how well they thought their organisation dealt with allegations of reprisals on a scale from 1 ('not at all well') to 5 ('extremely well'), the mean for all case-handlers fell below the midpoint of 'somewhat' $(2.82 ; \mathrm{n}=288)$, while the mean for all managers was the midpoint $(3 ; n=413)$. For the case-handlers and managers with direct experience of reprisal cases, the results were even less positive (for case-handlers, a mean of 2.60, $\mathrm{n}=148$; for managers, a mean of $2.75, \mathrm{n}=160$ ). Integrity case-handlers had an even more negative opinion of public sector organisations in their jurisdictions, perceiving that, on average, agencies dealt with allegations of reprisals 'not very well' (mean $=2.11, \mathrm{n}=73$; or, for those with direct experience, mean $=1.98, \mathrm{n}=53$ ). In fact, asked what proportion of agencies they believed had successfully dealt with alleged reprisals, 82 per cent of all integrity agency case-handlers estimated the proportion to be 'about one-quarter' or less (Q39). 
This low level of confidence in current responses to reprisals does not stem from any substantial view that the outcomes for whistleblowers are too favourable. While some respondents (notably, some managers) might believe this, the responses from all groups indicate that the majority are aware that presently, in the agencies studied, allegations of reprisal are only very occasionally substantiated. Instead, it is clear that most case-handlers, and even managers, agree that fewer allegations are currently substantiated than should be. Contrary to a stereotype of whistleblowers as prodigious complainants, a majority of case-handlers and managers ( 71 per cent) and integrity agency case-handlers (81 per cent) indicated a belief that at least 'sometimes' whistleblowers experienced reprisals but did not go on to report them.

Table 9.12 confirms that case-handlers and managers believe that the fact that few allegations are substantiated does not necessarily mean that no reprisal occurred. The table shows the reasons selected by case-handlers and managers with direct experience of reprisal cases, ranked in order of the perceived frequency with which the reason arises. Lack of real reprisal (that is, the allegation was wrong) was ranked as only the third most frequent reason by managers and integrity case-handlers and the fifth most frequent reason by case study case-handlers (arguably, those in the best position to form an objective view). The most common reason was lack of evidence, and several other reasons were also common, including inability to identify who was responsible and, for integrity case-handlers, inability to distinguish between legitimate and illegitimate actions against the whistleblower (presumably by management).

\section{Table 9.12 Reasons for unsubstantiated allegations of reprisal (mean)}

\begin{tabular}{|c|c|c|c|c|}
\hline $\begin{array}{l}\text { When allegations of reprisal have not been } \\
\text { substantiated, what are the most common } \\
\text { reasons for this finding? } \\
\begin{array}{l}1=\text { never; } \\
2=\text { rarely; } \\
3=\text { sometimes; } \\
4=\text { often; } \\
5=\text { always }\end{array}\end{array}$ & $\begin{array}{c}\text { Case-handlers } \\
(\mathrm{n}=136)\end{array}$ & $\begin{array}{l}\text { Managers } \\
(n=149)\end{array}$ & \begin{tabular}{|c|} 
Case-handlers \\
and managers \\
combined \\
$(n=285)$
\end{tabular} & $\begin{array}{c}\text { Integrity } \\
\text { case-handlers } \\
(n=49)\end{array}$ \\
\hline There was insufficient evidence & 3.42 & 3.33 & 3.37 & 3.67 \\
\hline $\begin{array}{l}\text { The employee subject to the reprisal did not want } \\
\text { it investigated }\end{array}$ & 3.29 & 3.13 & 3.21 & 2.43 \\
\hline There was no reprisal & 2.97 & 3.08 & 3.03 & 3.12 \\
\hline $\begin{array}{l}\text { There was evidence of a reprisal, but not enough } \\
\text { to identify or prosecute any individual(s) }\end{array}$ & 3.07 & 2.91 & 2.99 & 2.96 \\
\hline Passage of time prevented proper investigation & 3.07 & 2.89 & 2.98 & 2.92 \\
\hline $\begin{array}{l}\text { There was evidence of a reprisal, but also that } \\
\text { the same action could be reasonable or lawful }\end{array}$ & 2.76 & 2.62 & 2.69 & 3.18 \\
\hline
\end{tabular}

Sources: Case-handler and manager surveys: Q40; integrity case-handler survey: Q37.

Given the frequency with which management was identified as being responsible for the bad treatment reported in Chapter 5, the responses to this last item in Table 9.12 are particularly important. Unreasonable or inappropriate management 
action against a whistleblower can be a direct reprisal, or can represent simply the final stages in the unravelling of a whistleblowing case that is not, and perhaps cannot be, well handled. In any case, it will usually have bases that readily appear legitimate even if, overall, it is really the product of a state of affairs for which the agency should accept responsibility. Integrity case-handlers identified this problem as the second most frequent reason why allegations were not substantiated, and even though agency case-handlers and managers perceived it to be the least frequent reason, a majority (63 per cent) nevertheless agreed that it at least 'sometimes' happened.

Many case-handlers and managers went further and confirmed that they had experienced cases in which managers used disciplinary or personnel action as a 'cover' for a reprisal. In response to additional questions, 45 per cent of experienced case-handlers and managers indicated that it 'sometimes' or 'often' occurred that reprisals were alleged that were in fact legitimate disciplinary or personnel actions, but a large number (38 per cent) also saw the reverse as similarly common: disciplinary or personnel action was sometimes or often used 'as a cover for what is really just a reprisal' (Q39). Integrity case-handlers report an even more prevalent experience of both types of cases, with 91 per cent of experienced respondents agreeing that the former scenario sometimes or often arises and 75 per cent reporting the 'cover' scenario is similarly common (Q35; $\mathrm{n}=52)$.

These results highlight a number of challenges that could help explain why public sector organisations are - on their own account - struggling to provide more effective resolutions to these difficult problems. As with other forms of internal witness support, there are questions about the degree of effort and the adequacy of resources indicated by the current state of systems and procedures. As discussed in Chapter 5, there has been a misplaced assumption as to the most likely sources of reprisal risk that need to be addressed by agencies. The focus on the criminalisation of reprisals might not have helped their effective investigation by agencies, focusing as this does on establishing the responsibility of culpable individuals for deliberate acts, proven beyond a reasonable doubt. The more frequent problems are more complex, and sometimes simply negligent, management actions that are unlikely to ever be provable in that manner or to that standard, even when it is clear that a whistleblower has suffered undue detrimental outcomes as an overall result of management action, or inaction, in the course of the handling of the disclosure.

Some of these difficult issues can be addressed by agencies making more effort, filling gaps in their procedures, engaging in capacity building in the specialist area of reprisal investigation and taking a more flexible approach to investigations. The development of more effective support systems, as suggested in the first part of the chapter, should also relieve the opportunity and the need 
for individual managers to make some of the poor decisions that lead to justifiable allegations of reprisal. When the organisation is prepared to take more effective responsibility as a whole for the outcomes from the process-bad as well as good - there is less need for individual managers to feel that their inability to properly manage an individual case is their own responsibility.

The results also highlight the point at which internal agency systems often begin to be poorly placed to resolve issues on their own. Many agencies are clearly capable of receiving, investigating and resolving primary disclosures about internal wrongdoing. When issues arise about the adequacy of their management of the whistleblower, however, unless the case is relatively simple (that is, individual direct reprisals or obvious management lapses can be identified), internal processes are clearly less well placed to independently judge the extent to which things went wrong, for which the organisation itself should accept responsibility. The problem is that external integrity agencies are not currently well positioned, or perhaps well enough skilled, to fill this gap. While integrity case-handlers were highly critical of agencies' responses to reprisals, we saw in Chapter 8 that internal case-handlers were also highly critical of the contribution of the integrity agencies. Perhaps most importantly, while integrity case-handlers were naturally less sceptical of their own capacity than those in the agencies, they were still quite sceptical - like the internal case-handlers themselves in respect of their own role (integrity case-handler survey, Q41: mean $=3.11, \mathrm{n}=$ 73; for experienced, mean $=3.06, \mathrm{n}=53$ ).

As suggested also in Chapter 8, these data point to the need for a new relationship between agencies and integrity agencies in the way in which whistleblowing cases are managed - particularly when questions arise about the propriety of management reactions. While integrity agencies can and should continue to rely on line agencies to conduct their own investigations where appropriate, the evidence suggests a differentiated strategy is needed when issues arise about the adequacy of management responses in whistleblowing cases. At present, even if integrity agencies have the capacity, their involvement can simply come too late to help constructively resolve the true level of organisational responsibility for a whistleblower's problems. In cases in which conflict is well developed and bridges have already been burned between a whistleblower and their organisation, it can be that there are few remedies that an external investigation can realistically offer the whistleblower (as opposed to the agency and the public interest), with access needed instead to a different last line of 'appeal', such as a compensation umpire. These issues raise questions of statutory reform for discussion in Chapter 11 . 


\section{Discussion and conclusions}

This chapter has shown the large field of opportunity that exists for the development of more effective internal witness and whistleblower support programs, in public sector agencies in the jurisdictions studied.

The first part of the chapter showed that organised systems for supporting and protecting internal witnesses are in relative infancy. Only 54 per cent of all agencies surveyed had relevant procedures and only 11 per cent of all agencies surveyed had a formal internal witness support system. Moreover, even in the case study agencies, only a very small proportion of public interest whistleblowers - perhaps 1.3 per cent, or 6.5 per cent of all whistleblowers treated badly by management or colleagues - are estimated as having ever come into contact with those systems. The reasons for this low take-up of organised support services can include:

- the low level of resources dedicated to such programs

- a prior shortage of data regarding the overall level of whistleblowing

- uncertainty or confusion about the types of employees intended to be targeted by programs

- an absence or inadequacy of procedural guidance on how employees should access the support, including an over-reliance on whistleblowers' self-identifying as such for the purposes of gaining support

- lack of management information systems for ensuring that all deserving whistleblowing cases can be identified and assessed for support

- inadequate or misapplied statutory definitions.

The second part of the chapter documented the sources of support experienced by public interest whistleblowers and the types of strategies or methods used. Not surprisingly, given the first results, the main sources of support that currently prevent more whistleblowers from suffering are not organised support programs, but informal social and professional networks, including family, friends, colleagues, union officials and supervisors. These analyses also revealed that case-handlers and managers - while not excessively optimistic about their own success-nevertheless continue to overestimate the extent to which organised or official sources of support are helping prevent worse outcomes. This creates a high risk that support will fail in any of the many circumstances in which the dual role of direct supervisors and line managers, described in Chapter 7, can turn from positive to negative. There are also signs that strategies can be somewhat reactive and attuned to bolstering the coping skills of whistleblowers in order to help them 'tough out' difficult situations, rather than to management intervention against sources of conflict.

The third part of the chapter examined the measures taken to assess the risks of reprisal and other major problems and to respond to those threats. These results 
provided like evidence that agency systems are currently largely reactive. In the majority of agencies, there is little focus on thorough assessment of cases for the risks of what might go wrong, as opposed to providing support in the hope that nothing will.

Finally, the analyses show that when reprisal risks are realised, agency case-handlers and managers do not see themselves as very well equipped or well placed to deal with them. Their evidence confirms indications from Chapter 5 that, generally, allegations that whistleblowers have suffered reprisals or other management lapses are not currently handled well. The most common reasons why such allegations are only rarely substantiated are not that reprisals do not occur, but because of a range of difficulties in investigation, especially relating to the fact that most reprisals involve management reprisals and institutional reactions, not acts for which individuals can be held culpable to a criminal standard of proof.

This somewhat negative overall picture does not detract from the reality that in many agencies considerable efforts are taking place to develop more effective strategies of internal witness support. Nor does it suggest these efforts are not achieving success. Rather, it highlights the extent of the challenges faced by agencies and governments if such systems are to be properly developed and made to work. The second report from this project will examine in more detail the strategies and resources currently being used by many agencies to support and manage internal witnesses, with a view to better understanding current best practice. The analysis here has highlighted the importance of this approach, by demonstrating that many agencies are yet to even scratch the surface in this effort.

Overall, the results also suggest there are ready gains to be made by more public sector agencies in reducing the proportion of public interest whistleblowers who complain of mistreatment and in improving the reporting climate in organisations by developing more sophisticated support strategies. The results also suggest, however, that a new level of commitment is needed for this to occur.

The research now available confirms that the potential catchment of employees for which such strategies need to work is much larger and more diffuse through most organisations than previously believed. In addition to simply expanding the scale and scope of support programs in resource terms, there is a clear need for more effective management information systems, to support a new relationship between internal coordination points for investigations and support, and supervisors and line managers, who currently receive most disclosures and are the most crucial players in determining whether an internal witness will receive support or suffer reprisals. 
Similarly, the evidence suggests that some key developments in internal witness support are likely to hinge on regulatory and legislative reform. The low take-up of formal systems appears to be related to either restrictive statutory definitions of public interest disclosures, misapplication of those definitions or inadequate requirements for agencies to recognise, monitor and track disclosures. The patchy state of agency procedures and systems suggests a need for greater statutory guidance on agencies' employee support obligations and mechanisms for more effective external policy support and oversight. More effective handling of individual cases appears to rely on a new, differentiated relationship between agencies and integrity agencies, to lift the burden on the former by enabling the latter to provide more timely and useful assistance in difficult cases. These issues are further explored in the next two chapters.

Consistent with the aim of enabling more whistleblowers to accept an 'instrumental role' in the progress, support strategies need to be more proactive, involve more organised approaches to risk assessment and develop a new range of options for active intervention in the management of whistleblowing cases. Currently, it is likely because a large number of whistleblowing cases are easy to manage, or largely 'self-managing', that they do not lead to worse outcomes. By learning to supplement current support strategies with additional options for intervention, there is good reason to believe that agencies with higher proportions of problem cases can better encourage reporting and achieve greater workplace harmony. The feasibility of these objectives is explored further in the next chapter, in which further analysis shows that, statistically, those taking more effort to develop stronger whistleblowing procedures are indeed achieving better outcomes. 